\title{
An Investigation of the Relationship between Global Perspective and Willingness to Communicate in English in a Chinese University Context
}

\author{
Fan Fang ${ }^{1,2}$, Runting Chen ${ }^{1}$, Tariq Elyas ${ }^{2}$ \\ ${ }^{1}$ Shantou University \\ ${ }^{2}$ King Abdulaziz University
}

\begin{abstract}
Correspondence concerning this article should be addressed to Fan Fang, Department of Foreign Languages \& Literature, College of Liberal Arts, Shantou University, 243 Daxue Rd, Jinping District, Shantou, Guangdong Province, China, 515063.E-mail: ffang@stu.edu.cn
\end{abstract}

\begin{abstract}
In an era of increasing global connectivity, acquiring a global perspective (GP) and being able to communicate in English are important for both personal and professional development. People with a GP are expected to be more willing to engage in intercultural activities, and more willing to communicate in English. Although previous studies have focused on having a GP and willingness to communicate (WTC) in English, few have investigated whether there is a correlation between these two variables. This study, conducted at a Chinese university, aimed to determine the relationship between GP and WTC in English. Data were collected from students via a questionnaire $(n=114)$ and interviews $(n=7)$ at the end of the autumn semester in 2018. The findings demonstrate that the students' GP and their WTC in English through the English curriculum did not progress to a significant extent, and their GP and WTC in English were correlated. Furthermore, three themes that affected the interviewees' WTC were extracted from the interviews: global cognition, self-actualization, and intercultural experience. These findings suggest that it would be beneficial to learn English by developing a GP, and that educators can enhance students' WTC by helping them cultivate that perspective.
\end{abstract}

Keywords: english as a global language, english as a medium of instruction, english learning, english language teaching, global perspective, willingness to communicate in english

\section{Introduction}

Today, as the world is becoming increasingly interconnected, higher education has begun to pay attention to students' global learning and development (American Council on Education, 1995; Association of American Colleges \& Universities, 2007). Therefore, in addition to intellectual development, university students also need to gain a better sense of themselves and their relationships with others and the world. In other words, they need to cultivate a global perspective (GP) to develop as a global citizen, not only in language learning but also in general education (Baker \& Fang, 2019; Fang \& Baker, 2018; Goren \& Yemini, 2017;). As English has evolved as a global language in recent decades (Crystal, 2012), it has become more important to acquire a GP through the use of English. People from different lingua-cultures often use English as a common language to communicate if they do not know each other's native language (Seidlhofer, 2011). Moreover, English is the dominant language at many international universities, where it is often used as the medium of instruction (EMI) (Gundsambuu, 2019; Fang, 2018; Fenton-Smith, Humphreys \& Walkinshaw, 2017). In this sense, English is a tool for people to connect with the world and further their personal development.

The key to building connections with the world is engaging in communication with people from different cultural backgrounds. Thus, a willingness to communicate (WTC) in a second language (L2), defined as 'a readiness to enter into discourse at a particular time with a specific person' (MacIntyre, Dörnyei, Clément, \& Noels, 1998, p. 547), is essential for personal development because it enhances a person's ability to communicate with the world as a global citizen. However, while previous studies have addressed the theoretical foundation of GP and WTC, they have not sufficiently discussed the correlation between these two aspects. The present study, based 
on the context of a Chinese university, aims to determine the relationship between students' GP and WTC in English learning and identify any correlation between these two variables. The findings of this study could serve as a reference for educators to think about students' development and to reflect on their teaching. This study could also help bridge the gap between students' ability to learn English in school and their personal and professional development in their future career or educational endeavors that could make their English learning more sustainable.

\section{Literature Review}

\section{Global Perspective}

The meaning of GP varies in different research areas. The present study adopts the explanation of Braskamp, Braskamp, and Engberg (2014), who illustrate that GP is a holistic perspective on human development in the global world. According to their explanation, GP is grounded in two theoretical perspectives on personal development: intercultural maturity and intercultural communication. The first is based on the work, In Over our Heads, by Kegan (1994), who proposed that people need to rely on their feelings and relationships with others and their own thinking in their life journey. Kegan (1994) also put forward three domains of human development: cognitive, intrapersonal, and interpersonal, which were later adapted by King and Magolda (2005) to intercultural maturity, describing the social-cultural development of college students. As the second perspective, intercultural communication, posited by intercultural communication scholars, demonstrates an individual's intercultural competence and sensitivity (Bennett \& Bennett, 2004; Chen \& Starosta, 1996). These scholars identified three other domains of personal development: cognitive, affective, and behavioral, which, respectively, are similar to thinking, feeling, and relating and believed that through intercultural communication, the skills associated with these three domains will be strengthened.

In the present study, the perspectives on intercultural communication and intercultural maturity were integrated into a GP with Kegan's (1994) three domains. Figure 1 depicts the model of GP that encompasses three interconnecting circles. According to Braskamp et al. (2014), the cognitive (thinking) circle is about knowledge and epistemology; this means that one needs to take complexity and multiple cultural perspectives into consideration when viewing knowledge acquisition. The second circle, the intrapersonal (feeling) circle, stresses self-identity, awareness of personal values, and discovery of the purpose of life. The interpersonal circle includes communicating with people from different cultural backgrounds, relating to others, and accepting their differences.

Figure 1

The GP Model

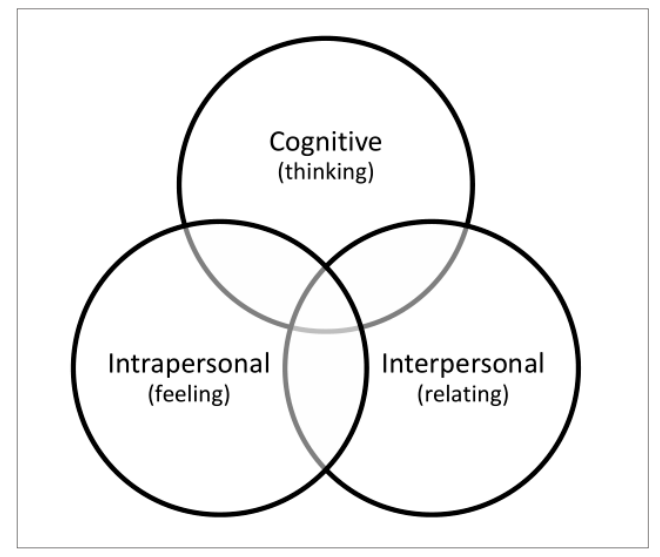

\section{L2 WTC and Other Related Concepts}

Originating from the concept of WTC in the first language (McCroskey, 1992; McCroskey \& Richmond, 1987), L2 WTC was initially defined as a stable, trait-like predisposition that was influenced by communication 
competency and communication anxiety (MacIntyre, 1994). L2 WTC was found to be affected by the interactions among various factors. For example, MacIntyre and Charos (1996) developed a model where L2 WTC was an integrative result of perceived L2 competence, motivation, L2 anxiety, integrativeness, and attitudes towards the learning situation. Later, MacIntyre et al. (1998) developed this model into a pyramid L2 WTC model (Figure 2) consisting of six layers, from the bottom layer that contained intergroup climate and personality, to the top layers containing L2 use. In this model, L2 WTC is not only a trait-like property, it also fluctuates according to different situations (see also Zhang, Beckmann \& Beckmann, 2019).

Figure 2

The Pyramid L2 WTC Model

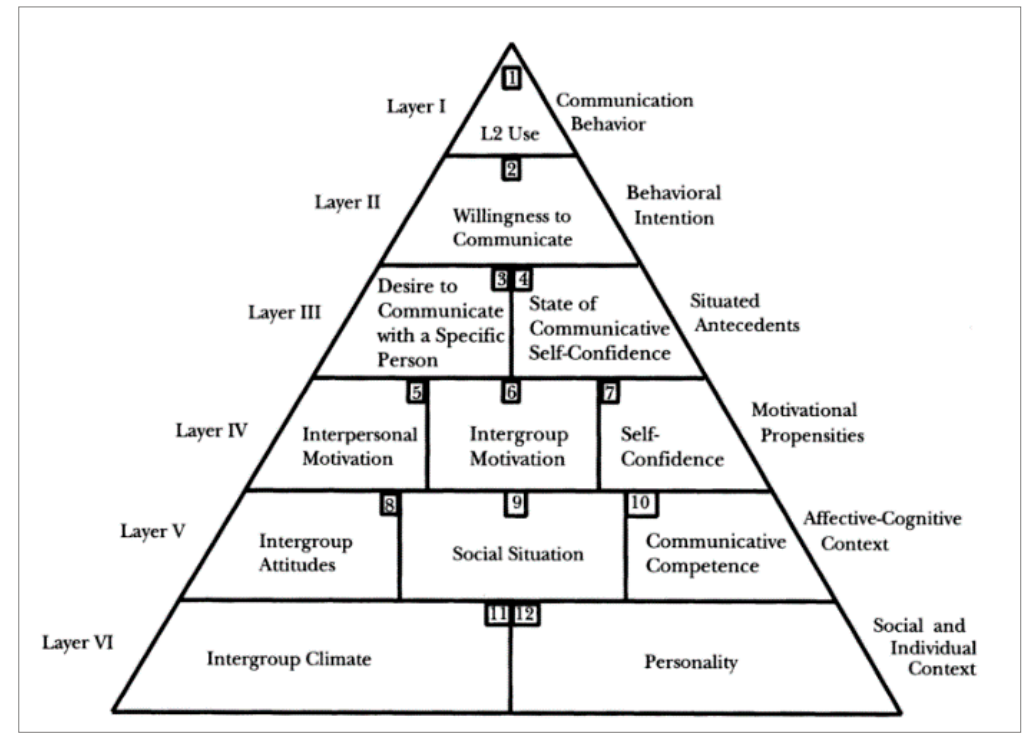

In the models mentioned above, integrativeness (intergroup motivation, intergroup attitudes, and intergroup climate) is one of the factors that influences L2 WTC. Integrativeness is associated with a learner's level of motivation for L2 learning. It refers to the inclination to approach an L2 group; thus, it will affect the L2 WTC (Gardner, 1985; MacIntyre \& Charos, 1996; Peng, 2014). Learning English in English-speaking countries provides learners with many opportunities to approach an L2 group. However, in the Asian context, where L2 English learners may lack access to an L2 group, the replacement of integrativeness was considered, and the notion of international posture was posited by Yashima (2002). Consisting of an interest in foreign or international affairs, the willingness to go overseas to live or work, the readiness to interact with intercultural partners, and an open attitude towards different cultures, Yashima used equation modelling to show that international posture helps increase L2 WTC. The idea of international posture links learners to a larger world, which is similar to the intercultural domains of GP. The present study expands the concept of international posture to GP, and it attempts to determine if there is congruity between the educational outcome and English learning. It also aims to identify the ways in which students are more willing to engage in English communication.

To investigate the relationship between GP and WTC, this study adopted a mixed-methods approach, including disseminating questionnaires and conducting interviews. By doing so, it provides an overview at the group level as well as depth at an individual level. Specifically, this study is based on the following research questions:

Q1: What is the difference between GP and L2 WTC among students with different levels of English proficiency?

Q2: To what extent, if any, is L2 WTC correlated with GP?

\section{Method}

\section{Research Context}

This study was conducted at a university located in southeast China at the end of the autumn semester in 2018. At this university, the English Language Center (ELC) is in charge of teaching English to all university students. 
The ELC has recruited teachers from both China and abroad, so the university is regarded as an emergent English as a lingua franca (ELF) community ${ }^{1}$. The goal of the ELC is to provide better teaching, facilitate an English learning environment, and enhance students' communication and critical thinking skills using creative and lively teaching activities. Every new student at this university must take an English placement test to determine their language proficiency level. Then, they can choose English classes based on their English proficiency level, and can also choose teachers using the school's registration system. Thus, students with different majors will take English classes together. At a minimum, students in all schools, except for the art school, have to pass ELC Level Four ${ }^{2}$ courses to achieve a higher-intermediate proficiency level in English upon graduation.

\section{Participants}

The participants in this study were all university students taking the ELC courses. For the questionnaire, the respondents consisted of 114 students from four different English classes: level one (29 students, 25.4\%), level two (30 students, $26.3 \%$ ), level three (26 students, $22.8 \%$ ), and level four ( 29 students, $25.4 \%$ ). Of the 114 students, 64 (56.1\%) were males and 48 (42.1\%) were females (two did not mention their gender in the questionnaire). The students were all non-English majors from the following schools: Liberal Arts, Law, Business, Science, Engineering, Journalism, and Art. In all four classes, the teachers were Chinese. Seven students participated in the interviews because they provided contact information and showed interests in participating in further research. Of those, five were selected from the students who had completed the questionnaire and two were English majors with study abroad experience who were contacted directly by the researchers. Three of the seven interviewed students were male and four were female.

\section{Instruments}

\section{Questionnaire}

The questionnaire, containing two parts, a GP scale and an L2 WTC scale, was administered to the participating students at the end of the autumn semester in 2018. Because the students had different language proficiency levels, the questionnaire was translated from English into Chinese. The questionnaire took around 10 to 15 minutes to complete, and it was carried out during the class break time of the English classes.

Students' GP was measured with the GP scale adapted from the Global Perspective Inventory (GPI) (2017), which assesses GP from cognitive, intrapersonal, and interpersonal dimensions. Each dimension is divided into two aspects; thus, the GPI consists of six scales. The questionnaire used in this study selected two of the six items from each scale based on the students' familiarity, so 12 items were adopted and rated using a 5-point Likert scale $^{3}$ (see Appendix 1 for the items).

For L2 WTC, items from Mystkowska-Wiertelak and Mirostaw (2017), concerning L2 WTC inside and outside the classroom, were used as the measures. Eight items were used: four L2 WTC inside the classroom items and four L2 WTC outside the classroom items according to students' experience and level of understanding. As some items on the original scale were not familiar to the students, the items were adapted to facilitate understanding. For example, the item, 'I am willing to use computer-mediated communication to address an acquaintance of mine', was changed to 'I am willing to communicate with a foreigner (teacher, friend, etc.) in English on the internet'. These items were piloted with a group of students and found to be valid. The L2 WTC items were rated on a 6-point Likert scale ${ }^{4}$ (see Appendix 1 for the items).

\section{Interviews}

This study used semi-structured interviews because this method enables researchers to collect similar data from different interviewees while facilitating the flexibility to ask follow-up questions and discover unexpected areas.

\footnotetext{
1 ELF is defined as 'any use of English among speakers of different first languages for whom English is the communicative medium of choice, and often the only option' (Seidlhofer, 2011, p. 7).

2 After completing the ELC courses and passing Level Four, students are expected to achieve English proficiency at an IELTS 6-6.5 (CEFR B2) level.

3 The five-point scale is measured as: 1 strongly disagree, 2 disagree, 3 neither agree nor disagree, 4 agree, or 5 strongly agree (see Research Institute for Studies in Education, 2017).

4 The six-point scale is measured as: 1 definitely not willing, 2 probably not willing, and 3 perhaps not willing 4 perhaps willing, 5 probably willing, or 6 definitely willing (see Mystkowska-Wiertelak \& Pawlak, 2017)
} 
The interviews were conducted after disseminating the questionnaire. The first round of interviews involved five students who completed the questionnaire, and it focused on the same themes (see the interview prompts in Appendix 2) related to their WTC in English and GP. In addition to these questions, follow-up questions were also asked based on the interviewees' answers and personal experiences. The second round of interviews was conducted with two senior English majors who had a study abroad experience. In addition to the questions listed above, this interview also focused on their study abroad experiences. In conducting the interviews, this study tried to determine the interaction between L2 WTC in English and GP. All the interviews were audiorecorded and then transcribed by the researchers with the permission of the participants.

\section{Questionnaire results}

\section{Results}

Statistical Package for the Social Sciences (SPSS) Version 16.0 was adopted to analyze the questionnaire data. The coefficient reliability of the GP and L2 WTC scales was measured, and their Cronbach $\alpha$ was .71 and .92, respectively, which are acceptable (Hair et al., 2010). The GP and L2 WTC of every participant were assessed by calculating the mean scores of all the items in each scale. Next, based on the two previously mentioned research questions, a One-Way Analysis of Variance (ANOVA) and Pearson Correlation Analysis were run.

The first research question is about the difference between GP and L2 WTC among students with different English proficiency levels. Because this requires examining the differences among more than two groups, and the result of the One-sample Kolmogorov-Smirnov test (Table 1) met the distribution assumption (Asymp. Sig. (2-tailed) > .05), ANOVA was chosen. Table 2 shows the means of the GP and L2 WTC scores of the students with different English proficiency levels. The mean of GP ranged from 3.17 to 3.47 for the four English proficiency levels, and L2 WTC ranged from 4.33 to 4.73 . The results do not change much based on the students' English proficiency levels. Table 3 describes the result of the One-Way ANOVA among the students with different English proficiency levels. The statistics indicate that there was no significant difference in GP and L2 WTC among students from all four English proficiency levels.

Table 1

Results of the One-sample Kolmogorov-Smirnov Test

\begin{tabular}{lcc}
\hline & GP & L2 \\
& MEAN & WTC MEAN \\
\hline Asymp.Sig. (2-tailed) & .155 & .243 \\
\hline
\end{tabular}

Table 2

Means of GP and L2 WTC of Students with Different English Proficiency Levels

\begin{tabular}{lccc}
\hline & & N & Mean \\
\hline GP & level 1 & 28 & 3.47 \\
& level 2 & 29 & 3.40 \\
& level 3 & 25 & 3.17 \\
& level 4 & 28 & 3.43 \\
L2 WTC & level 1 & 28 & 4.67 \\
& level 2 & 30 & 4.73 \\
& level 3 & 26 & 4.33 \\
& level 4 & 29 & 4.55 \\
\hline
\end{tabular}


Table 3

Results of One-Way ANOVA among Students with Different English Proficiency Levels

\begin{tabular}{llccc}
\hline & & df & F & sig \\
\hline GP & Between Groups & 3 & 2.458 & .067 \\
& Within Groups & 106 & & \\
& Total & 109 & & \\
L2 WTC & Between Groups & 3 & .836 & .477 \\
& Within Groups & 109 & & \\
& Total & 112 & & \\
\hline
\end{tabular}

The second research question aimed to determine if L2 WTC is correlated with GP. Figure 3 shows the simple scatter plot between GP and L2 WTC, which indicates that there may be a weak to moderate positive correlation between the two variables (Field, 2005). After obtaining an overview from the scatter plot, a Pearson product moment correlation analysis was run in SPSS to examine the degree of the correlation between GP and L2 WTC. As seen in Table 4, in this study, L2 WTC was significantly correlated with GP $(\mathrm{r}=.47, \mathrm{p}<.05)$. The effect size of the correlation between these two variables, according to Field (2005), reaches the medium effect size $(r=0.3)$.

Figure 3

Scatter Plot between GP and L2 WTC

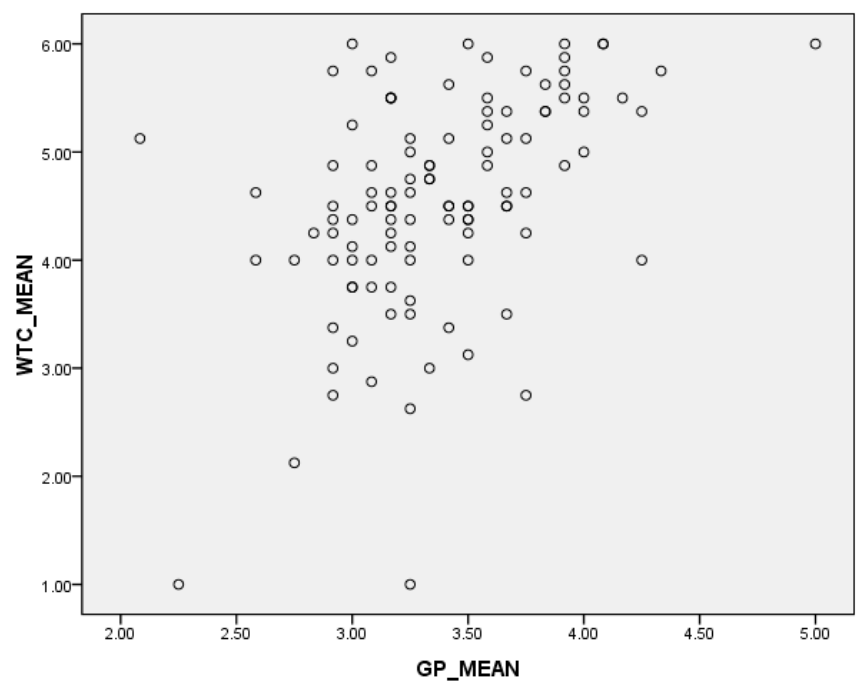

Table 4

Results of the Pearson Correlation Analysis of GP and L2 WTC

\begin{tabular}{lcccc}
\hline & Mean & SD & GP & L2 WTC \\
\hline GP & 3.37 & .45 & 1 & \\
\hline L2 WTC & 4.57 & 1.00 & $.47^{* * *}$ & 1 \\
\hline
\end{tabular}

\section{Interview Findings}

After collecting the questionnaire data, five questionnaire participants (denoted as Participant A, Participant B, Participant C, Participant D, and Participant E) were invited for a first-round interview based on their GP and WTC scores obtained from the questionnaire. Because participants F and Participant G did not complete the questionnaire but had study abroad experience, they were scheduled for the second-round interview, the focus of which was different from the first round. Table 5 shows the GP and WTC scores from the questionnaires of the interviewees, excluding Participant F and Participant G. The audio recordings of the interviews were transcribed in Chinese and stored in NVivo 11. This study then used latent content analysis (Dörnyei, 2007) to identify essential themes that are related to the research questions and emergent issues. Thus, it adopted both 
top-down coding based on the research questions and bottom-up coding based on the interviewees' answers (Miles et al., 2014). The coding scheme was developed with 26 codes under five themes: global cognition, selfactualization, intercultural experience, WTC in English, and English learning. A student who had taken a Research Methodology course was invited to read the coding scheme for one of the interviews, and an acceptable level of agreement was reached (86\%). The following section outlines the relationship between GP and L2 WTC in English summarized from the responses from the seven interviewees.

Table 5

\begin{tabular}{lcc}
\multicolumn{3}{c}{ Interviewees' Scores of GP and WTC in English } \\
\hline Interviewee & $\begin{array}{c}\text { GP Score } \\
\text { (full score: 60) }\end{array}$ & $\begin{array}{c}\text { WTC Score } \\
\text { (full score: 48) }\end{array}$ \\
\hline Participant A & 33 & 17 \\
Participant B & 56 & 46 \\
Participant C & 40 & 24 \\
Participant D & 40 & 44 \\
Participant E & 49 & 47 \\
\hline
\end{tabular}

\section{Global Cognition and WTC in English}

The theme of global cognition corresponds to the cognition domain of GP, which is about thinking in a complex and multicultural way. The interview participants were asked if they were interested in international news and cultures of different countries. None of the participants had the habit of following international news, but some of them, occasionally paid attention to international breaking news. In particular, Participant $\mathrm{C}$ followed some news stories in WeChat because she thought it would be useful for her further study and future career:

\section{Extract 1:}

I follow several public accounts, such as thepaper.cn and huanqiu.com. Why did I pay attention to this news at the beginning? Because I wanted to take the civil servant exam and a postgraduate entrance exam at that time. I could pay attention to some public accounts. I think foreign news is okay.

Participant F expressed that she did not pay much attention to international affairs but mentioned that she would keep an eye on news related to China instead:

\section{Extract 2:}

I don't really follow international news. Instead, I will focus on the topic of China, and it will also involve some foreign views. Take China's democracy as an example; I want to know what the point of view of foreigners is.

When asked about their interest in foreign cultures, most of the interviewees, such as Participant E, did not pay much attention to other cultures:

\section{Extract 3:}

I pay some attention, but not much attention. I do not pay much attention to these cultures. Sometimes, when I watch videos or programs, I find their concepts are different from ours. I think it's very interesting, and I go to watch them.

Participant $\mathrm{G}$ expressed her curiosity about foreign cultures:

\section{Extract 4:}

I'm interested in other people's cultures...Maybe it's because of curiosity, because the country itself has diversity, and then you listen to them talk about their culture, there will be a lot of different stories. 
In terms of WTC in English, Participant C's questionnaire score and interview responses showed that she did not have a strong need to communicate in English:

\section{Extract 5:}

At present, I do not have much desire to communicate with foreigners. Let's just say, I'm open to it... I was really nervous in the middle of the semester, because I felt that the students in front of me spoke very well, and this semester was very special. Just one of my classmates and I were sophomores in our class, and the others were freshmen. Besides, because they reached level two when they first entered the school, I felt they were really cool. And then it felt a little bit off. I seldom spoke English in class.

Similarly, Participant F did not demonstrate much WTC in English, except for classes where English is needed. However, Participant E and Participant G both expressed their WTC in English and with foreigners:

\section{Extract 6:}

Interviewer: Do you take the initiative to find opportunities to chat with others in English?

Participant G: Yes, especially in English classes or with people who can speak English. Not with someone who does not speak English.

Interviewer: With native speakers?

Participant G: Not necessarily. As far as I know they can speak English. If I'm sure other people do not speak English, I don't.

\section{Extract 7:}

Interviewer: Do you like to talk with others in English?

Participant E: Yeah, I like to talk to my roommates in English when I am free.

Interviewer: Is it a deliberate exercise, or is it just for fun?

Participant E: Both. For example, after watching a TV show, I also want to learn to speak. As usual, I speak English, and then I can improve my spoken English. Indeed, speaking English is also a necessary skill.

Interviewer: What other reasons do you have for learning English besides this ability?

Participant E: The most obvious reason is that it's cool. If you speak in English, people think this person is awesome.

These excerpts demonstrate that most of the interviewees are not interested in global affairs and foreign cultures. Even if they follow international news, as Participant $\mathrm{C}$ did, they did so for practical reasons, such as preparing for exams. For the participants, things that are happening in other countries are not pertinent, and compared their immediate or vital interests, this type of news and information about other cultures is not necessary in their life.

\section{Self-Acutalization and WTC in English}

In the present study, the concept of self-actualization refers to a person's expectation of himself/herself and how he/she fulfills his/her goals, especially in English and for life-long planning. Thus, self-actualization can also refer to the intrapersonal domain in GP. To determine one's self-actualization, the participants in this study were asked the following questions: 1) What is the role of English in your life now and in the future and 2) what is your goal in learning English?

For Participant A, English does not matter much for his future goals, and he is not interested in it. As an engineering student who is going to apply for a job after earning his bachelor's degree, the College English Test Band 6 certificate was sufficient for him, and he would probably stop learning English in the future. He mentioned: 'I'm not interesting in speaking English because I don't have interest in it.' As English is a compulsory subject for all the university students, he is simply not motivated to learn English. Participant D was not clear about what role English would play in her future:

Extract 8: 
Interviewer: Do you have a plan for your future career? What would English be used for in your future?

Participant D: Because I do not know whether I will go abroad in the future, I do not have plans in this regard.

Interviewer: In addition to an overseas exchange program, do you think English will be helpful for your future work? Or will you not use English in the future?

Participant D: In terms of employment, it depends on what companies I will work for. Because some enterprises may need to use English to communicate.

Interviewer: Do you intend to join international corporations?

Participant D: It's not clear yet.

In contrast, participant B was clearer about the role of English in his future:

Extract 9:

Certainly, I will keep learning English. After all, it doesn't matter what you want to do in the future. I want to study psychology in the future. For example, in the field of psychology, foreign studies, foreign experiments, and conclusions are much better than those in China. It is difficult to translate the latest foreign achievements into Chinese. If you are engaged in this field, and you want to get the latest conclusions, information, and theories, then you must have a good ability to read English literature. I think that is a necessary ability for you to work in any industry in the future and broaden your horizon.

Participant B did not indicate his WTC in English in the interview, but his scores in the L2 WTC questionnaire were reasonably high. However, he expressed that he would seldom use English in China and he did not like to learn English simply for passing exams. While participant C did not clearly state her L2 WTC, she has joined some English organizations where she needed to speak English:

Extract 10:

Interviewer: Do you like to communicate with others in English?

Participant C: I have joined several organizations where I need to communicate in English.

Interviewer: What organizations?

Participant C: The Case Study Group and English Lounge, but now I have to quit.

Interviewer: How did it feel in English Lounge?

Participant C: I think it is listening that helps me a lot.

Interviewer: What about speaking?

Participant C: I think it creates an environment for people to speak, but there are about 20 people in one activity, so not everyone has the chance to talk. We mainly lead others to speak.

In terms of WTC in English, participant A is not interested in anything related to English. However, if communicating in English is needed, he would comply:

\section{Extract 11:}

Interviewer: Have you ever tried to communicate with others in English?

Participant A: It is required in class. Sometimes, I meet some foreigners outside of class and need to communicate with them.

Interviewer: Have you ever had such an experience?

Participant A: Yes.

Interviewer: Are you able to communicate with them?

Participant A: I've basically tried it twice and I think I understood their English.

Interviewer: Do you think it feels good to talk to people in English?

Participant A: No, it's frightening, really. Because many people cannot speak English, at least I can. One time, no one could speak English to a foreigner, because many of them were middleaged. Then, they grabbed me and said you should be young enough to speak English, so I said a few words. 
In conclusion, Participant A and Participant B were both clear about their future use of English, although Participant A considered English to be useful in his future life while Participant B considered it to be useless, except for passing exams. Participant $C$ has not made a decision about what she will do in the future. The complexity of self-actualization and WTC was revealed from the participants' comments.

\section{Intercultural Experience and WTC in English}

Intercultural experience is about meeting with people from other countries or cultural backgrounds; it is related to the interpersonal perspective in GP because it involves person-to-person communication (Jackson, 2020). Because most of the participants were freshmen and sophomores, their only chance to communicate in English was in their English class. They seldom talked with foreign teachers or students because they were afraid of being embarrassed if they could not understand what is being said.

\section{Extract 12:}

Interviewer: Are there any foreign teachers in your specialized courses?

Participant B: Yes, but I'm afraid to go. I'm afraid I will not understand.

\section{Extract 13:}

Interviewer: Are there any foreign teachers in your specialized courses?

Participant C: At present, I have had three semesters of English classes, and two of them were taught by Chinese teachers. I think Chinese teachers are a little better. For example, if there are some important questions that some people may not understand in English, I can say the important parts again in Chinese. I think this is very good, and it may be better for me. I also chose the courses taught by a Chinese teacher next semester.

Extract 14:

Interviewer: Have you ever met some foreign teachers and foreign students when you entered the university and then tried to communicate with them in English?

Participant E: Yes, but I seldom take the initiative. When I go to some English events, I meet foreign teachers and foreign students. I don't usually communicate with them.

Unlike the other interview participants, participants $\mathrm{F}$ and $\mathrm{G}$ are seniors who have both had several study abroad experiences. Participant F has taken part in two short projects in Nepal and Germany, respectively. According to her interview responses, these experiences enabled her to see what other countries are actually like, and she also thought that English would be beneficial if she chose to work abroad in the future. However, she does not have much interest in communicating with people from other countries because of her shyness and her fear of misunderstanding what is being said. Participant $G$ joined an exchange program that enabled her to study at an American university for one semester. In the interview, she shared her interest in talking with people from different countries because she liked to learn about other people's cultures. She made several friends in America who were from different countries, and their conversations usually went well because her English did not impede communication, and she was able to handle the situation.

\section{Discussion}

In comparison with international posture (Yashima, 2002), GP includes the intercultural communication perspective as well as cognition and the interpersonal perspective. If people think globally, feel clear about their identity in the world, and hope to engage in intercultural communication, it is necessary for them to communicate in English (Pawlak \& Mystkowska-Wiertelak, 2015; Peng, 2014, 2019). EMI education might be proved helpful and effective for those students' English learning journey. Therefore, the present study suspected that there is a link between GP and L2 WTC. 
From the questionnaire results, the correlation coefficient between GP and L2 WTC in English indicates that, in the context of one Chinese university, a student with a high GP may be more likely to communicate in English. Inversely, a student who has high L2 WTC in English could possibly have a broader GP than those with lower L2 WTC in English. When English serves as a lingua franca to communicate with the world rather than a knowledgebased skill, GP and L2 WTC in English are probably correlated. The One-Way ANOVA analysis showed that there was no significant difference in GP and WTC among students with different English proficiency levels. In this study, both the mean scores of GP and L2 WTC in English were above the medium score (GP: 3.17-3.47 on a 5-point scale, L2 WTC: $4.33-4.73$ on a 6-point scale). This also means that students may not make enough progress in GP and L2 WTC, which should be an important educational outcome of learning English. From level 1 to level 4, the students may still not be aware of their English-learning goals, and they may acquire knowledge about the English language but still not have a high level of WTC in English with others.

From the interview excerpts related to global cognition and WTC in English, it was found that all of the interviewees except Participant G, did not have strong global cognition, but their L2 WTC varied because their interest in and fear of talking in an L2 may have been impacted by other variables, such as a sense of being cool (Participant E) and a lack of confidence (Participant C). However, in Participant G's case, her interest in foreign cultures prompted her to communicate with foreigners in English, which indicates that a global cognition may enhance one's L2 WTC.

From the interview excerpts related to self-actualization and WTC in English, Participant B's case indicates that if people know why they need to learn English and why English is so important, they may have a greater WTC in English because the recognition of English will enhance their WTC. Participant A's case reveals the opposite; if one does not recognize the importance of the role that English plays in personal and professional development, it is difficult to embrace English, which impacts their WTC. However, although Participant C did not articulate her purpose for learning English, she joined English clubs where she can cultivate her ability to communicate in that language. This may be due to her personal interests and the environment in which she is learning English.

The interview excerpts related to intercultural experience and WTC in English, revealed that language can be either a barrier or a bridge to intercultural communication (Fang \& Baker, 2018). For the participants who consider their English to be insufficient, English is a barrier to engaging in intercultural communication, such as communicating with foreign teachers or students. Even though some of them have a high WTC in English, their willingness does not overcome their fear of being embarrassed. However, for Participant G, who overcame those worries, language is a bridge that connects her to the world, helping her communicate with people from different countries. In turn, this intercultural experience may also enhance WTC and improve communication skills (Fang \& Baker, 2018).

The results and findings of the questionnaire and the interviews suggest that there is room for students and educators to improve the English learning process, and students' WTC can be enhanced by cultivating their GP (Fang \& Baker, 2018; Baker \& Fang, 2019; Yashima, MacIntyre \& Ikeda, 2018). On the one hand, students need to treat English as a communication tool from a sociocultural perspective, rather than as a subject and an exam they have to take. If their learning in English is limited to an exam-oriented and knowledge-based perspective, they may easily feel less motivated to learn English, and they might not realize the fun and importance of communicating, which is more essential for their English progress (Peng, 2014). On the other hand, educators could attempt to stimulate students' GP in class by discussing international affairs and foreign cultures, inviting students to talk about their goal of learning English, creating a communicative environment, and so on (see e.g., Peng, 2012, 2014; Yashima, MacIntyre \& Ikeda, 2018). However, we need to realize that WTC and GP are both dynamic concepts, as students' 'momentary psychological reactions to contextual factors both facilitated and constrained their participation in the discussions, showing interesting situational dynamics' (Yashima et al., 2018, p. 132). Further understanding of the relationship between WTC and GP will help both teachers and students explore the concept of global citizenship education (Goren \& Yemini, 2017; Fang \& Baker, 2018). 


\section{Conclusion}

Before making any conclusions, we will recognize some limitations of this study. Currently, the theoretical foundation of the relationship between GP and WTC is insufficient. Therefore, further research is needed to support the causality between these two variables. To determine the cause-effect relationship, the number of questionnaire and interview participants needs to be enlarged in the future. In particular, more interview data can be helpful for better understanding the correlation between GP and WTC. Moreover, because this study only involved classes taught by Chinese teachers, additional studies should include classes taught by international teachers.

In a non-English-speaking country such as China, being able to communicate in English is essential for a person who has a GP. Likewise, with a GP, a learner may be more willing to communicate in English than those who are unclear about their life goals and are not interested in engaging in global issues in the future. The present study found that GP and L2 WTC in English are two correlated variables, and there is room for students and educators to improve these two aspects in their learning and teaching. If students could make sense of the role of English in their life, they could practice their English in a more effective way than is possible if they only follow their teachers' instruction. If educators could use English classes and activities to activate the students' WTC in English and help them cultivate a global perspective, they might contribute to students' life-long development and facilitate a sustainable way for them to learn English.

\section{Funding}

This work was supported by the "The 13th Five-Year Plan Education and Science Special Research Projects on Philosophy and Social Science of Higher Education (2019)", Department of Education of Guangdong Province - "Effectiveness of the Implementation of English as a Medium in Higher Education of Guangdong Province" [Grant No.: 2019GXJK194].

\section{Conflict of Interest}

The authors declare that they have no conflict of interest.

\section{References}

American Council on Education. (1995). Educating Americans for a world in flux: Ten ground rules for internationalizing higher education. https://files.eric.ed.gov/fulltext/ED388165.pdf

Association of American Colleges and Universities (2007). Global learning for the new global century: Executive summary with findings from employer survey. https://www.aacu.org/sites/default/files/files/LEAP/ GlobalCentury_final.pdf

Baker, W., \& Fang, F. (2019). From English language learners to intercultural citizens: Chinese student sojourners' development of intercultural citizenship in ELT and EMI programmes. British Council.

Bennett, J. M. \& Bennett, M.J. (2004). Developing intercultural sensitivity: An integrative approach to global and domestic diversity. In D. Landis, J. M. Bennett \& M. J. Bennett (Eds.), Handbook of intercultural training (3rd ed., pp. 147-165). Sage.

Braskamp, L. A., Braskamp, D. C., \& Engberg, M. E. (2014). Global Perspective Inventory (GPI): Its purpose construction, potential uses, and psychometric characteristics. Global Perspective Institute.

Braskamp, L. A., Braskamp, D. C., \& Merrill, K. C. (2009). Assessing progress in global learning and development of students with education abroad experiences. Frontiers: The Interdisciplinary Journal of Study Abroad, 18, 101-118.

Chen, G. M. \& Startosta, W. (1996). Intercultural communication competence: A synthesis. Communication 


\section{INVESTIGATION OF THE RELATIONSHIP BETWEEN GLOBAL PERSPECTIVE AND WILLINGNESS}

Yearbook, 19, 353-383. https://doi.org/10.1080/23808985.1996.11678935

Crystal, D. (2012). English as a Global Language (2nd edn.). Cambridge University Press.

Dörnyei, Z. (2007). Research methods in applied linguistics. Oxford University Press.

Fang, F. (2018). Review of English as a medium of instruction in Chinese universities today: Current trends and future directions. English Today, 34(1), 32-37. https://doi.org/10.1017/S0266078417000360

Fang, F., \& Baker, W. (2018). 'A more inclusive mind towards the world': English language teaching and study abroad in China from Intercultural citizenship and English as a lingua franca perspectives. Language Teaching Research, 22(5), 608-624. https://doi.org/10.1177/1362168817718574

Fenton-Smith, B., Humphreys, P. \& Walkinshaw, I. (Eds.). (2017). English medium instruction in higher education in Asia-Pacific. Springer.

Field, A. (2005). Discovering statistics using SPSS (2nd ed.). SAGE Publications.

Gardner, R. C. (1985). Social psychology and second language learning: The role of attitudes and motivation. Edward Arnold.

Goren, H., \& Yemini, M. (2017). Global citizenship education redefined - A systematic review of empirical studies on global citizenship education. International Journal of Educational Research, 82, 170-183. https:// doi.org/10.1016/j.ijer.2017.02.004

Gundsambuu, S. (2019). Internationalization and English as a medium of instruction in Mongolian higher education: A new concept. Journal of Language and Education, 5(2), 48-66. https://doi.org/10.17323/ jle.2019.8481

Hair, J. F., Black, W. C., Babin, B. J., \& Anderson, R. E. (2010). Multivariate data analysis (7th ed.). Prentice Hall.

Jackson, J. (2020). Introducing language and intercultural communication (2nd ed.). Routledge.

Kegan, R. (1994). In over our heads: The mental demands of modern life. Harvard University Press.

King, P., Magolda, M.B.B. (2005). A developmental model of intercultural maturity. Journal of College Student Development, 46, 571-592. https://doi.org/10.1353/csd.2005.0060

MacIntyre, P. D. (1994). Variables underlying willingness to communicate: A causal analysis. Communication Research Reports, 11(2), 135-142. https://doi.org/10.1080/08824099409359951

MacIntyre, P. D., \& Charos, C. (1996). Personality, attitudes, and affect as predictors of second language communication. Journal of Language and Social Psychology, 15, 3-26. https://doi. org/10.1177/0261927X960151001

MacIntyre, P. D., Dörnyei, Z., Clément, R., \& Noels, K. A. (1998). Conceptualizing willingness to communicate in a L2: a situational model of L2 confidence and affiliation. The Modern Language Journal, 82(4), 545-562. https://doi.org/10.1111/j.1540-4781.1998.tb05543.x

MacIntyre, P. D., \& Legatto, J. J. (2011). A dynamic system approach to willingness to communicate: Developing an idiodynamic method to capture rapidly changing affect. Applied Linguistics, 32(2), 149-171. https://doi. org/10.1093/applin/amq037

McCroskey, J.C. (1992). Reliability and validity of the willingness to communicate scale. Communication Quarterly, 40, 16-25. https://doi.org/10.1080/01463379209369817

McCroskey, J.C., \&Richmond, V.P. (1987). Willingness to communicate. In J.C. McCroskey \& J.C. McCroskey \& J.A. Daly (Eds.), Personality and interpersonal communication (pp. 129-156). Sage.

Miles, M, Huberman, M., \& Saldaña, J. (2014). Qualitative data analysis: A methods sourcebook (3rd edn). Sage.

Mystkowska-Wiertelak, A., \& Pawlak, M. (2017). Willingness to communicate in instructed second language acquisition: Combing a macro- and micro-perspective. Multilingual Matters.

Pawlak, M., \& Mystkowska-Wiertelak, A. (2015). Investigating the dynamic nature of L2 willingness to communicate. System, 50, 1-9. https://doi.org/10.1016/j.system.2015.02.001

Peng, J. (2012). Towards an ecological understanding of willingness to communicate in EFL classrooms in China. System, 40, 203-213. https://doi.org/10.1016/j.system.2012.02.002

Peng, J. (2014). Willingness to communicate in the Chinese EFL university classroom. Bristol: Multilingual Matters.

Peng, J. (2019). Understanding willingness to communicate as embedded in classroom multimodal affordances: Evidence from interdisciplinary perspectives. Linguistics and Education, 51, 59-68. https://doi.org/10.1016/j. linged.2019.04.006

Research Institute for Studies in Education (2017). Global Perspective Inventory: Theoretical foundations and scale descriptions. . Iowa State University. https://www.gpi.hs.iastate.edu/documents/GPI\%20Theory\%20and\%20 Scales.pdf

Seidlhofer, B. (2011). Understanding English as a lingua franca. Cambridge University Press.

Yashima, T. (2002). Willingness to communicate in a second language: The Japanese EFL context. The Modern Language Journal, 86(1), 54-56. https://doi.org/10.1111/1540-4781.00136 


\section{FAN FANG, RUNTING CHEN, TARIQ ELYAS}

Yashima, T., MacIntyre, P., \& Ikeda, M. (2018). Situated willingness to communicate in an L2: Interplay of individual characteristics and context. Language Teaching Research, 22(1), 115-137. https://doi. org/10.1177/1362168816657851

Zhang, J., Beckmann, N., \& Beckmann, J. F. (2019). One situation doesn't fit all: Variability and stability of state willingness to communicate in a Chinese college English classroom. Language Teaching Research. https://doi. org/10.1177/1362168819891330 


\section{Appendix 1}

\section{The Questionnaire}

\section{Part I:}

The following scales describe how you think, how you view yourself, and how you relate to others who are different. Please circle the number that best describes your opinion: 1 strongly disagree, 2 disagree, 3 neither agree nor disagree, 4 agree, or 5 strongly agree.

1. I consider different cultural perspectives when evaluating global problems.

$$
\begin{array}{lllll}
1 & 2 & 3 & 4 & 5
\end{array}
$$

2. I rely primarily on authorities to determine what is true in the world. (r)

$$
\begin{array}{lllll}
1 & 2 & 3 & 4 & 5
\end{array}
$$

3. I am informed about current issues that impact international relations.

$$
\begin{array}{lllll}
1 & 2 & 3 & 4 & 5
\end{array}
$$

4. I understand the causes of conflict among nations with different cultures.

$$
\begin{array}{lllll}
1 & 2 & 3 & 4 & 5
\end{array}
$$

5. I know who I am as a person.

$$
\begin{array}{lllll}
1 & 2 & 3 & 4 & 5
\end{array}
$$

6. I am willing to defend my views when they differ from others.

$\begin{array}{lllll}1 & 2 & 3 & 4 & 5\end{array}$

7. I am sensitive to those who are discriminated against.

$\begin{array}{lllll}1 & 2 & 3 & 4 & 5\end{array}$

8. I am open to people who strive to live lives very different from my life.

$\begin{array}{lllll}1 & 2 & 3 & 4 & 5\end{array}$

9. I think of my life in terms of giving back to society.

$\begin{array}{lllll}1 & 2 & 3 & 4 & 5\end{array}$

10. I work for the rights of others.

$\begin{array}{lllll}1 & 2 & 3 & 4 & 5\end{array}$

11. I frequently interact with people from a race/ethnic group different from my own. $\begin{array}{lllll}1 & 2 & 3 & 4 & 5\end{array}$

12. I intentionally involve people from many cultural backgrounds in my life.

$$
\begin{array}{llllll}
1 & 2 & 3 & 4 & 5
\end{array}
$$

\section{Part II:}

The following statements describe tasks or situations inside an English class and outside the classroom. Please circle the number that best describes your opinion: 1 definitely not willing, 2 probably not willing, and 3 perhaps not willing 4 perhaps willing, 5 probably willing, or 6 definitely willing.

1. I am willing to present my arguments to the rest of my class in English.

$$
\begin{array}{llllll}
1 & 2 & 3 & 4 & 5 & 6
\end{array}
$$


2. I am willing to give a presentation in front of the class in English.

$\begin{array}{llllll}1 & 2 & 3 & 4 & 5 & 6\end{array}$

3. I am willing to participate in a small-group discussion in English.

$\begin{array}{llllll}1 & 2 & 3 & 4 & 5 & 6\end{array}$

4. I am willing to ask the teacher in English to repeat what $\mathrm{s} /$ he said.

$\begin{array}{llllll}1 & 2 & 3 & 4 & 5 & 6\end{array}$

5. I am willing to communicate with a foreigner (teacher, friend, etc.) in English on the internet. $\begin{array}{llllll}1 & 2 & 3 & 4 & 5 & 6\end{array}$

6. I am willing to initiate communication with a foreigner I met on the street.

$\begin{array}{llllll}1 & 2 & 3 & 4 & 5 & 6\end{array}$

7. I am willing to speak to a foreigner who asks for help (e.g., help him/her find directions).

$\begin{array}{llllll}1 & 2 & 3 & 4 & 5 & 6\end{array}$

8. If given the opportunity, I am willing to speak to exchange students in English.

$\begin{array}{llllll}1 & 2 & 3 & 4 & 5 & 6\end{array}$

\section{Appendix 2}

\section{Interview Prompts}

1. How often and in what circumstance are you willing to communicating with others in English?

2. Have you ever tried to communicate with others in English in different situations?

3. How are you willing to communicate with people from different countries in English?

4. What is the role of English in your life now and in the future? 